\title{
Isolated sphenoid inflammatory diseases associ- ated with visual impairment: 15-year experience at a single institution*
} \author{
Semeraro $^{2}$, D. Farina ${ }^{3}$, P. Nicolai ${ }^{1}$ \\ Department of Otorhinolaryngology, University of Brescia, Italy \\ 2 Department of Ophthalmology, University of Brescia, Italy \\ 3 Department of Radiology, University of Brescia, Italy
}

A. Bizzoni ${ }^{1}$, A. Bolzoni Villaret ${ }^{1}$, D. Lombardi ${ }^{1}$, D. Tomenzoli ${ }^{1}$, P. Danzi ${ }^{2}$, F.

SUMMARY

We present a retrospective series of 11 patients treated for isolated sphenoid inflammatory disease (ISID) with visual impairment in the period between 1994 and 2008. The series included 7 females and 4 males. All patients, preoperatively assessed by CT and / or MR, underwent endoscopic sinus surgery and broad-spectrum antibiotic therapy. The procedure was always performed in an emergency setting, with an interval from the onset of visual impairment ranging between 1 and 40 days (mean 9 days). The possibility of recovery was related to both the modality of onset and severity of the deficit. All patients with reduction of the visual field reported significant improvement after surgery. Patients with decreased visual acuity obtained partial or complete resolution, while in patients with preoperative blindness no improvement was observed. Moreover, no postoperative improvement was noticed in the case of severe deficits with sudden onset, whereas the treatment of mild deficits was successful even some weeks after their occurrence. In conclusion, although some factors may predict the likelihood of recovery, any patient with ISID associated with visual impairment should receive immediate medical and surgical treatment. Endoscopic surgery should be considered the technique of choice.

Key words: sphenoid inflammatory disease, orbital complications, visual loss, endoscopic sinus surgery

\section{INTRODUCTION}

Isolated sphenoid inflammatory disease (ISID) is an uncommon pathology, with a reported prevalence ranging from 1 to $3 \%$ of all patients affected by sino-nasal diseases ${ }^{(1)}$. In up to $10 \%$ of cases, it is associated with severe ocular signs and symptoms such as oculomotor nerve palsy or visual loss, which can be the only presenting complaint ${ }^{(2)}$. The frequent absence of any sinonasal symptom explains why patients are in general addressed to the otorhinolaryngologist only after CT or MR has been performed to exclude a central nervous system disorder and a sphenoid sinus disease is identified.

The management of these patients is challenging because treatment should be started as soon as possible to reduce the risk of permanent visual deficit ${ }^{(3)}$. The only effective therapy is sinusotomy with drainage of secretions together with intravenous administration of broad-spectrum antibiotics and steroids. The time interval from the onset of visual impairment, its rapidity of onset and entity have been suggested as predictors of successful treatment ${ }^{(3-5)}$. In this report, we present the experience at our Institution in the management of ISID associated with visual impairment, to better define the role of endoscopic sinus surgery and to assess the impact of early diagnosis and treatment on outcome.

\section{MATERIALS AND METHODS}

Study design

We retrospectively reviewed the clinical records of patients who underwent surgery at the Department of Otolaryngology of the University of Brescia (Italy) for inflammatory diseases of the sino-nasal tract in the period between January 1994 and June 2008 to identify patients with ISID associated with visual disturbances characterized by an acute onset. The presenting signs and symptoms, the time interval between clinical presentation and surgical procedure were evaluated.

\section{Patients}

All patients underwent preoperative ophthalmologic evaluation, including visual acuity, anterior and posterior segment examination, pupillary reflex, tonometry, and ocular motility. CT scan, possibly associated with MR, was obtained in all cases (Figure 1). Whenever a diagnosis of sphenoid sinusitis was suggested, patients received an endoscopic sphenoidotomy, via a paraseptal or transethmoidal approach, 
according to the anatomy of the patient and the presence of scar tissue due to previous surgery. Intravenous antibiotic and steroid treatment was immediately started in all cases. High dose anti-staphylococcal agents such as second or third generation cephalosporin (cefotaxime $2 \mathrm{gr}$ twice daily) or clindamycin and dexamethasone ( $8 \mathrm{mg}$ once daily) were commonly administered. All patients underwent postoperative ophthalmologic evaluation to monitor the visual acuity and field. Moreover, periodic transnasal endoscopic controls were performed to remove crusts and fibrin and allow ventilation of the sinus tract. Each patient was followed for at least 1 year (range: 12 - 70 months).

\section{RESULTS}

Of 3697 patients who received surgery for inflammatory diseases of the sinonasal tract, $98(2.6 \%)$ presented an isolated sphenoid disease that was complicated by visual impairment in $11(11.2 \%)$ cases. Four $(36.4 \%)$ were males and $7(63.6 \%)$ females, with an age ranging from 11 to 82 years (mean: 52 years). Two $(18.2 \%)$ patients had already undergone previous endoscopic surgery for chronic inflammatory disease at another Institution.

Nine $(81.8 \%)$ patients complained of impaired visual acuity (bilateral in two cases), whereas a reduction of the visual field was reported in two cases $(18.2 \%)$ (Table). In one case (9.1\%), impairment of color discrimination was reported. Ophthalmologic evaluation findings are summarized in Table 1. The interval between the appearance of visual symptoms and surgery ranged from 1 to 40 days (mean: 9 days). Associated complaints included headache in $6(54.5 \%)$ patients, nasal obstruction and periorbital pain in $3(27.3 \%)$ cases each.

Preoperative imaging studies included CT in all cases, associated with MR in $5(45.5 \%)$. In $6(54.5 \%)$ patients, preoperative imaging findings showed a dehiscence of the lateral wall of the sphenoid sinus, with the optic nerve in close contact with the inflammed mucosa. Imaging findings were consistent with sphenoid mucocele in 5 cases $(45.5 \%)$, nonspecific sphenoiditis in $5(45.5 \%)$ cases, and fungus ball in 1 patient $(9 \%)$. Preoperative transnasal endoscopic evaluation was negative in all cases but one $(9 \%)$, in whom a purulent discharge from the spheno-ethmoid recess was observed. According to ophthalmologic, imaging, and endoscopic findings a diagnosis of retrobulbar optic neuropathy (RON) due to ISID was made in all cases.

Table 1. Patient population.

\begin{tabular}{|c|c|c|c|c|c|c|c|c|}
\hline $\begin{array}{l}\text { Age, } \\
\text { Gender }\end{array}$ & Side & $\begin{array}{l}\text { Onset } \\
\text { (Days) }\end{array}$ & Ocular Symptoms & $\begin{array}{c}\text { Other } \\
\text { Symptoms }\end{array}$ & $\begin{array}{c}\text { Preop Visual } \\
\text { Acuity and Field }\end{array}$ & $\begin{array}{c}\text { Postop Visual } \\
\text { Acuity and Field }\end{array}$ & $\begin{array}{c}\text { Sinus } \\
\text { Pathology }\end{array}$ & Outcome \\
\hline $11, \mathrm{~F}$ & Right & 30 & $\begin{array}{l}\text { Decreased visual } \\
\text { acuity }\end{array}$ & $\begin{array}{c}\text { Headache, nasal } \\
\text { obstruction }\end{array}$ & $\begin{array}{l}\text { R eye: } 1 \backslash 20 \\
\text { L eye } 10 \backslash 10\end{array}$ & R eye: $10 \backslash 10$ & Sinusitis & $\begin{array}{l}\text { Complete } \\
\text { recovery }\end{array}$ \\
\hline $74, \mathrm{~F}$ & Left & 2 & $\begin{array}{c}\text { Dyschromia, } \\
\text { decreased visual } \\
\text { acuity }\end{array}$ & Headache & $\begin{array}{l}\mathrm{L} \text { eye } 2 \backslash 10 \\
\mathrm{R} \text { eye } 7 \backslash 10\end{array}$ & L eye: $7 \backslash 10$ & Mucocele & Partial recovery \\
\hline $80, \mathrm{M}$ & Bilateral & 10 & $\begin{array}{c}\text { Decreased visual } \\
\text { acuity }\end{array}$ & Headache & $\begin{array}{l}\text { No light } \\
\text { perception }\end{array}$ & $\begin{array}{l}\text { No light } \\
\text { perception }\end{array}$ & Invasive mycosis & No recovery \\
\hline $49, \mathrm{~F}$ & Left & 20 & $\begin{array}{l}\text { Decreased visual } \\
\text { field, proptosis }\end{array}$ & Headache & $\begin{array}{l}\text { L eye: } 10 \backslash 10 \text {, } \\
\text { scotoma }\end{array}$ & $\begin{array}{l}\text { Reduction of } \\
\text { scotoma }\end{array}$ & Mucocele & Partial recovery \\
\hline $29, \mathrm{~F}$ & Right & 40 & $\begin{array}{l}\text { Decreased visual } \\
\text { acuity }\end{array}$ & $\begin{array}{c}\text { Headache, nasal } \\
\text { obstruction }\end{array}$ & $\begin{array}{c}\text { R eye } 3 \backslash 10 \\
\text { L eye: } 10 \backslash 10\end{array}$ & R eye: $10 \backslash 10$ & Sinusitis & $\begin{array}{l}\text { Complete } \\
\text { recovery }\end{array}$ \\
\hline $48, \mathrm{M}$ & Bilateral & 1 & Blindness & $\begin{array}{l}\text { Headache, } \\
\text { periorbital pain }\end{array}$ & $\begin{array}{c}\text { No light } \\
\text { perception }\end{array}$ & $\begin{array}{l}\text { No light } \\
\text { perception }\end{array}$ & Mucocele & No recovery \\
\hline $58, \mathrm{~F}$ & Right & 10 & Blindness & - & $\begin{array}{c}\text { R eye: hand } \\
\text { movement } \\
\text { L eye }: 7 \backslash 10\end{array}$ & $\begin{array}{l}\text { No light } \\
\text { perception }\end{array}$ & Mucocele & No recovery \\
\hline $51, \mathrm{M}$ & Right & 7 & $\begin{array}{l}\text { Decreased visual } \\
\text { acuity }\end{array}$ & Periorbital pain & $\begin{array}{l}\text { R eye: no light } \\
\text { perception } \\
\text { L eye: } 8 \backslash 10\end{array}$ & $\begin{array}{l}\text { No light } \\
\text { perception }\end{array}$ & Mucocele & No recovery \\
\hline $40, \mathrm{M}$ & Left & 7 & $\begin{array}{l}\text { Decreased visual } \\
\text { field }\end{array}$ & - & $\begin{array}{c}\text { L eye: deficit } \\
\text { inferior squares }\end{array}$ & $\begin{array}{l}\text { Reduction of } \\
\text { deficit }\end{array}$ & Fungus ball & Partial recovery \\
\hline $82, \mathrm{~F}$ & Right & 2 & $\begin{array}{l}\text { Decreased visual } \\
\text { acuity }\end{array}$ & Periorbital pain & $\begin{array}{l}\text { R eye: } 1 \backslash 50 \\
\text { L eye: } 9 \backslash 10\end{array}$ & R eye: $7 \backslash 10$ & Mucocele & Partial recovery \\
\hline $53, \mathrm{~F}$ & Left & 30 & Blindness & Nasal obstraction & $\begin{array}{c}\text { L eye: blindness } \\
\text { R eye: } 8 \backslash 10\end{array}$ & Blindness & Mucocele & No recovery \\
\hline
\end{tabular}

Table 1. Patient population. Legend: R: right; L: left. 


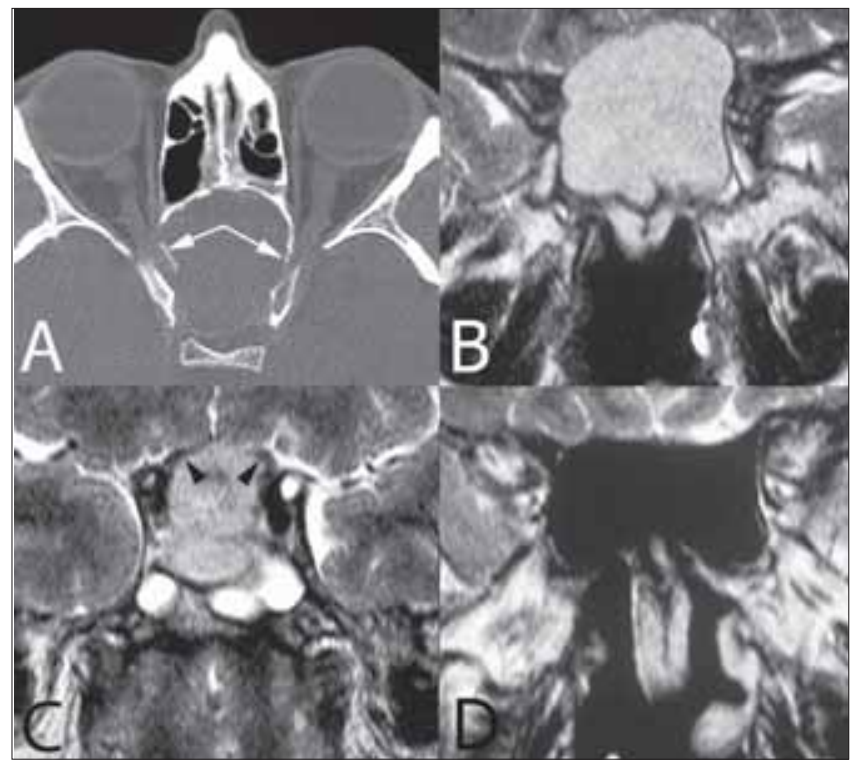

Figure 1 (A-D). Plain CT on axial plane (A), TSE T2 on coronal plane (B-C), post operative survey (D). The sphenoid sinus is expanded by a large mucocele; bone walls are remodelled, both optic canals (arrows) and optic tracts (arrowheads) are compressed. After surgery, the sinus cavity shows normal size and shape with no residual inflammation.

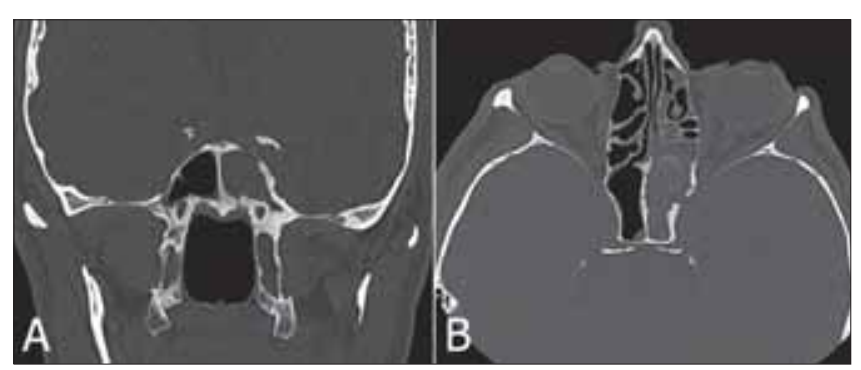

Figure 2 (A-B). Plain CT on coronal (A) and axial plane (B). Complete opacification of the sphenoid sinus, the subtle calcifications seen in the anterior part of the sinus cavity herald a fungal infection. Bone is extensively remodelled, both sclerosis and demineralization are detected.

All patients underwent endoscopic sphenoid sinusotomy with debridement of sinus content; a sample of sphenoid sinus mucosa was sent for histological examination in all cases. When a mycosis was suspected at imaging or intraoperative evaluation, the material inside the sinus was also analyzed. Based on intraoperative and histological findings, the final diagnosis was mucocele or mucopyocele in $7(64 \%)$ patients, acute sinusitis in $2(18 \%)$, and fungus ball and chronic indolent mycosis in $1(9 \%)$ case each. No perioperative complications were observed; permanent patency of sphenoidotomy was obtained in all cases.

Postoperative ophthalmologic evaluation showed visual improvement in $6(55 \%)$ patients, 4 of $9(44.4 \%)$ with visual acuity impairment and $2(100 \%)$ with visual field reduction. In the 5 patients ( 4 mucoceles and 1 invasive mycosis) who did not experience any improvement, the time interval between onset of symptoms and surgery ranged between 1 and 30 days. The two patients with reduction of visual field had partial or complete recovery (Table). All cases with recovery of vision reported significant improvement of vision the day after surgery.

\section{DISCUSSION}

ISID is a rare clinical condition, often associated with chronic or recurrent headache that is not responsive to analgesics, and only rarely complicated by visual disturbance ${ }^{(6)}$ that, at least in our experience, can be the symptom leading to diagnosis. In fact, nasal endoscopy may not show any findings suggestive for sphenoid inflammatory disease. In our experience, in $1(9 \%)$ patient only a purulent discharge from the sphenoethmoid recess was observed. Whenever a visual deficit occurs, ophthalmologic examination is mandatory to estimate the entity of visual loss ${ }^{(4,5,7)}$ and to address the diagnosis.

In visual disturbances due to sphenoid inflammatory diseases, the optic pathway is involved at the level of the retrobulbar portion of the optic nerve. Several authors have speculated on the possible causes of visual loss in patients affected by spheno-ethmoidal diseases ${ }^{(4,5,20)}$ and two primary etiopathogenetic mechanisms for RON have been forwarded. The first hypothesizes a direct compression ischemia by an expansile lesion (compressive neuropathy), whereas the second one involves ischemic infarction due to thrombophlebitis or vasculitis ${ }^{(4)}$ (optic neuritis). The latter is favored by the delicate vascular pattern of the optic nerve inside the bony canal. Both conditions entail one or more of the following complaints: visual loss, visual field defect, acquired dyschromatopsia, and afferent papillary defects ${ }^{(4)}$. In the presence external compression, optic disk congestion and/or retrobulbar compression may also be observed ${ }^{(4)}$. It is worth mentioning that in mucocele, the most frequent non-neoplastic sphenoid expansile lesion, the neuropathy may be due not only to a direct compression but also to a local inflammatory effect. Moreover, the occurrence of a sudden, complete, and often irreversible visual loss is explainable only with a vascular damage.

RON may be also related to other pathologies, such as demyelinizing conditions. Additionally, retinal artery or vein occlusion may simulate an optic neuropathy; in these cases, a definitive diagnosis may be reached by fluoroangiography. Since clinical findings are limited and non-specific, diagnosis is achieved by imaging studies (CT and/or MR), possibly in an emergency setting. CT may show total or partial opacification of the sphenoid sinus ${ }^{(8)}$, which may or may not be associated with alterations of bony walls (erosion, sclerosis) and/or anatomic anomalies predisposing to optic neuritis ${ }^{(8)}$. MR is generally performed to rule out the suspect of a demyelinizing disease or a neoplastic lesion; ISID displays a high homogeneous signal intensity and low signal intensity on T2- and T1-weighted sequences, respectively. In contrast, in the presence of a sphenoid fungus ball, the CT profile includes, besides sinus opacification, bone remodeling (erosion and or 
thickening and sclerosis) and microcalcifications ${ }^{(9)}$ (Figure 2). At MR, a hypointense lesion bordered by hyperintense and enhancing mucosa on T2- and T1 weighted sequences, respectively, is observed; a so-called 'void signal' may be detected in up to $50 \%$ of the patients with sphenoid sinus fungus ball ${ }^{(9)}$.

All the 11 patients of the present series had visual loss as the main ophthalmologic finding, and a diagnosis of RON was established; papillary reflex was absent in $4(36 \%)$ cases. A diagnosis of sphenoiditis was made by CT and/or MR performed in an emergency setting in all cases. In six patients, a time interval longer than 1 week (up to 40 days) between visual loss onset and diagnosis and treatment was observed.

All our patients underwent endoscopic surgery immediately after a diagnosis of ISID was made, in combination with intravenous antibiotics and steroid therapy. Antibiotic treatment is recommended as the first-line treatment and should be started immediately to avoid potential severe morbidity and mortality ${ }^{(10-12)}$. Even though there has been no clear demonstration of actual benefit, we also advocate steroid administration, which is aimed at reducing optic nerve damage, either on a compressive or vascular basis.

With regards to surgical treatment, in 3 cases we performed a transnasal paraseptal approach, whereas a trans-ethmoidal approach was elected in 8 patients because of the anatomy of the patient and/or the presence of scar tissue due to previous surgery. A purely endoscopic approach can be nowadays considered the gold standard in the management of the entire spectrum of ISIDs, from sphenoid mucocele ${ }^{(5,13-16)}$ to sphenoid sinusitis ${ }^{(17,18)}$ and mycotic lesions ${ }^{(19)}$, even in a pediatric population ${ }^{(8)}$. The advantages of an endoscopic approach to the sphenoid sinus are the magnification of the surgical field, multiprospective vision thanks to angled scopes, the opportunity to perform surgery under local anesthesia in very selected cases, low morbidity, absence of scars, low complication rate, and short hospitalization time ${ }^{(13)}$. Our experience of a case of chronic indolent mycosis not clearly diagnosed by imaging studies emphasizes the need to send tissue samples for histopathologic examination in order to establish a correct diagnosis.

In $6(55 \%)$ cases, preoperative imaging and/or intraoperative findings showed a dehiscence of the lateral wall of the sphenoid sinus with direct contact between the nerve and the inflammatory process. All these patients reported a sudden onset of visual symptoms. Significant improvement in visual acuity was observed in only 4 cases. The two patients who did not show any improvement were those with absence of pupillary reflex and blindness at presentation.

In our experience, the most important factor predicting a favorable outcome was not the time between the onset of symptoms and surgery, but rather the entity and rapidity of onset of visual loss. Poor prognosis was associated with more severe and rapid visual loss. This can explain why we observed recovery in patients referred to the Hospital even 40 days after a slowly progressing and incomplete visual loss had appeared. When sudden blindness was observed, surgery and intravenous antibiotic therapy performed even after a few hours may not result in satisfactory outcome.

Our functional results compare favorably with those reported in the literature, as we observed good visual outcome in $55 \%$ of cases ${ }^{(3,4,7)}$. These data and assumptions are in agreement with other papers addressing the importance, on one hand, of the entity and onset modality of visual loss and, on the other, of the rapidity of surgery as key factors to decrease the possibility of irreversible damage ${ }^{(5)}$.

Whenever visual disturbance due to a sphenoid inflammatory process is observed, prompt intravenous broad-spectrum antibiotic and steroid therapy is required, and surgical sphenoidotomy by an endoscopic approach should be performed. Immediate surgery is justified even when there is a long time interval between the onset of visual impairment and diagnosis.

\section{REFERENCES}

1. Zheng-Min W, Nayouki K, Chung-Fu D, et al. Isolated sphenoid sinus disease: an analysis of 12 cases. Ann Otol Rhinol Laryngol. 2002; 111: 323-327.

2. Lawson W, Reino AJ. Isolated sphenoid sinus disease: an analysis of 132 cases. Laryngoscope. 1997; 107: 1590-1594.

3. Ruoppi P, Seppa J, Pukkila M, Nuutinen J. Isolated sphenoid sinus disease. Arch Otolaryngol Head Neck. 2000; 126: 777-781.

4. Lee LA, Huang CC, Lee TJ. Prolonged visual disturbances secondary to isolated sphenoid sinus disease. Laryngoscope. 2004; 114: 986-990.

5. Moriyama H, Hesaka H, Tachibana T, Honda Y. Mucoceles of ethmoid and sphenoid sinus with visual disturbances. Otolaryngol Head Neck Surg. 1992; 118: 142-146.

6. Guvenc MG, Kaytaz A, Acar GO, Ada Mehmet. Current management of isolated sphenoiditis. Eur Arch Otorhinolaryngol. 2009; 266: 987-992.

7. Yumoto E, Hyodo M, Kawakia S, Aibara R. Effect of sinus surgery on visual disturbance caused by spheno-ethmoid mucoceles. Am J Rhinol. 1997; 11: 337-343.

8. Berlucchi M, Rossini M, Bondioni MP, Nicolai P. Isolated acute sphenoiditis with viual loss: a rare disorder in pediatric patients. Int Journal Ped Otorhinolaryngol Extra. 2008; 3: 132-135.

9. Nicolai P, Lombardi D, Tomenzoli D, et al. Fungus ball of the paranasal sinuses: experience in 160 patients treated with endoscopic surgery. Laryngoscope. 2009; 119: 2275-2279.

10. Lew D, Southwick FS, Montgomery WW, Weber AL, Baker AS. Sphenoid sinusitis. A review of 30 cases. N Engl J Med. 1983; 309: 1149-1154.

11. Cohen YH, Amir J, Zeharia A, Danziger Y, Ziv N, Mimouni M. Isolated sphenoidal sinusitis in children. Eur J Pediatr. 1999; 158: 298-304.

12. Urquhart AC, Fung G, McIntosh WA. Isolated sphenoiditis: a diagnostic problem. J Laryngol Otol. 1989; 103: 526-527.

13. Benninger MS, Marks S. The endoscopic management of sphenoid and ethmoid mucoceles with orbital and intracranial extension. Rhinology. 1995; 33: 446-452.

14. Har-El G. Endoscopic management of 108 sinus mucoceles. Laryngoscope. 2001; 111: 2131-2134.

15. Ikeda K, Takahashi C, Oshima T, et al. Endonasal endoscopic 
marsupialization of paransal sinus mucoceles. Am J Rhinol. 2000; 14: 107-111.

16. Loehrl TA, Leopold DA. Sphenoidal mucocele presenting with bilateral visual compromise. Ann Otol Rhinol Laryngol. 2000; 109: 608-610.

17. Castelnuovo P, Pagella F, Semino L, et al. Endoscopic treatment of isolated sphenoid sinus lesions. Eur Arch Otorhinolaryngol. 2005; 262: 142-147.

18. Metson R, Gliklich R. Endoscopic treatment of sphenoid sinusitis. Otolaryngol Head Neck Surg. 1996; 114: 736-744.

19. Nicolai P, Tomenzoli D, Berlucchi M, et al. Il trattamento endoscopico dell'aspergilloma sfenoidale. Acta Otorhinolaryngol Ital. 1998; 18: 23-29.

20. Moorman CM, Anslow P, Elston JS. Is sphenoid sinus opacity significant in patients with optic neuritis? Eye. 1999; 13: 76-82.
Davide Lombardi, MD

Department of Otorhinolaryngology

University of Brescia

Piazza Spedali Civili 1

25123 Brescia

Italy

Tel: +39-(0)30-399 5319

Fax +39-(0)30-399 5212

E-mail davinter@libero.it

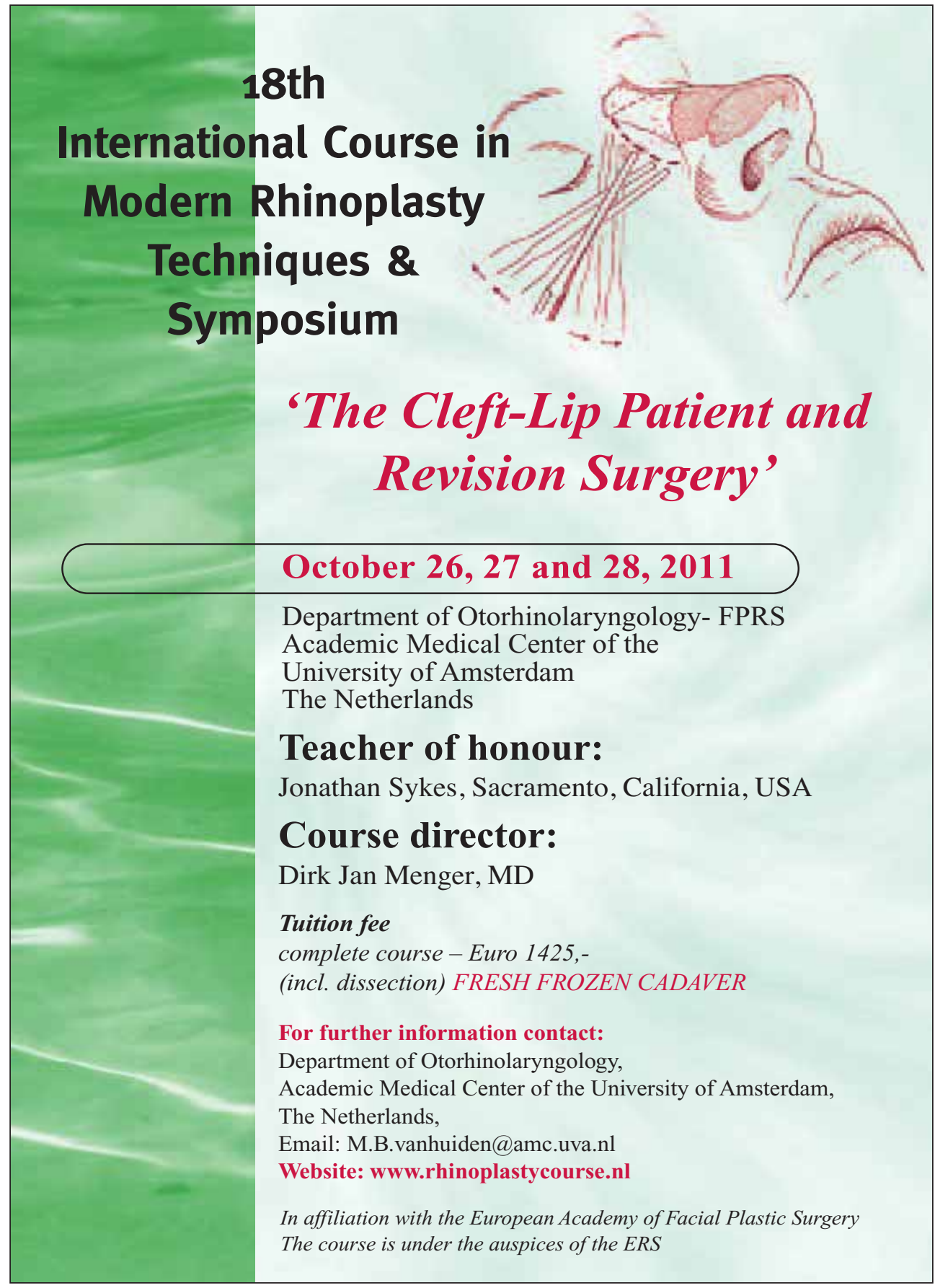

